\title{
Report of Objective Clinical Responses of Cancer Patients to Pharmaceutical-grade Synthetic Cannabidiol
}

\author{
JULIAN KENYON ${ }^{1}$, WAI LIU ${ }^{2}$ and ANGUS DALGLEISH ${ }^{2}$ \\ ${ }^{1}$ The Old Brewery, Winchester Hants, U.K.; \\ ${ }^{2}$ St George's University of London, London, U.K.
}

\begin{abstract}
Background/Aim: Cannabinoids are widely used in the management of pain, nausea and cachexia in cancer patients. However, there has been no objective clinical evidence of any anticancer activity yet. The aim of this study was to assess the effects of pharmaceutical-grade synthetic cannabidiol on a range of cancer patients. Patients and Methods: We analysed the data routinely collected, as part of our treatment program, in 119 cancer patients over a fouryear period. Results: Clinical responses were seen in $92 \%$ of the 119 cases with solid tumours including a reduction in circulating tumour cells in many cases and in other cases, a reduction in tumour size, as shown by repeat scans. No sideeffects of any kind were observed when using pharmaceutical grade synthetic cannabidiol. Conclusion: Pharmaceuticalgrade synthetic cannabidiol is a candidate for treating breast cancer and glioma patients.
\end{abstract}

The phytocannabinoids are a group of chemicals extracted from the cannabis plant. A number of them are able to impede cancer cell growth, induce apoptosis and autophagy, and inhibit angiogenesis. The most widely known phytocannabinoid is $\Delta 9$-tetrahydrocannabinol (THC), and although it possesses these anticancer effects, it is also psychoactive, which has arguably hampered its clinical development. It is thought that these actions are mediated, in part, by binding to cannabinoid receptors that are expressed on a number of tissue types (1). As one type of the receptor is found exclusively on brain cells, studies using THC have focused on this tissue type. In vitro data were promising and, in 2016, a pilot clinical study in patients with glioblastoma

This article is freely accessible online.

Correspondence to: Dr. Julian Kenyon, The Old Brewery, High Street, Twyford, Winchester Hants SO21 1RG, UK. Tel: +44 01962 718000, Fax: +44 01962 717060, e-mail: jnkenyon@doveclinic.com

Key Words: Cancer, cannabinoids, ependymoma, prostate cancer, breast cancer. multiforme indicated THC was safe; however, no clear activity was reported (2). The dosages were possibly on the conservative side, to minimise psychoactivity that would naturally restrict the use of THC as drug.

Of the $80+$ phytocannabinoids, THC is possibly the only one to exhibit this psychoactivity. More recently, studies have diverted away from THC and focussed on other cannabinoids. The next most abundant compound is cannabidiol (CBD), which has a low affinity for the canonical cannabinoid receptors. In contrast to THC, in its pure state, according to the World Health Organisation, CBD did not have abuse potential and caused no harm (3). Studies have shown that in addition to being able to induce cell death directly, it is also capable of interfering with intracellular signalling (4). Alterations to pathways such as the PI3K/AKT/mTOR and the ERK, suggests that CBD can modify the way certain cancer cells react to other treatments. Indeed, studies have shown that combining CBD with conventional chemotherapy such as cytarabine and vincristine can lead to enhanced anticancer activity through modifications to these signalling pathways $(5,6)$. Furthermore, the sequence in which these drugs are administered can also influence overall activity (5). Studies have also indicated that in certain leukaemia cell lines, CBD can increase the expression of the cyclindependent kinase inhibitor $\mathrm{p} 21^{\text {wafl }}(6)$. This increased level appears to be maintained by $\mathrm{CBD}$, which inadvertently impedes cell death. Cytotoxicity can be restored in these cells if the treatment regimen was altered to allow for a temporary cessation of exposure to CBD. Thus, the general efficacy of CBD may also be altered by adapting treatment protocols that include "drug-free" phases (6).

The findings of a number of studies designed to examine the role of cannabinoids in in the management of cancer symptoms varied (7). The most recent prospective analysis of nearly 3,000 patients using medical marijuana showed that a large proportion of patients reported improvement in their condition (8). Patients often feel that conventional therapies are not working for them, and so they search the internet for alternative medicines. It is here that they find stories about cannabis working in patients with cancer, and understandably 
Table I. Tabular presentation of our results on 119 cancer patients.

\begin{tabular}{|c|c|c|c|c|c|c|c|c|c|}
\hline $\begin{array}{l}\text { Cancer } \\
\text { type }\end{array}$ & $\begin{array}{c}\text { Tumour } \\
\text { free }\end{array}$ & $\begin{array}{l}\text { Stable } \\
\text { disease }\end{array}$ & $\begin{array}{l}\text { Extended median } \\
\text { survival }\end{array}$ & $\begin{array}{c}\text { Slowed } \\
\text { progression }\end{array}$ & $\begin{array}{l}\text { No effect/ } \\
\text { result }\end{array}$ & Died & $\begin{array}{l}\text { CBD as only } \\
\text { treatment }\end{array}$ & $\begin{array}{l}\text { Unknown } \\
\text { outcome }\end{array}$ & $\begin{array}{l}\text { Total } \\
\text { cases }\end{array}$ \\
\hline Anaplastic ependymoma & & & 3 & & & & 3 & & 3 \\
\hline DIPG & & & 1 & & & & 1 & & 1 \\
\hline Glioblastoma multiforme & & & 4 & 3 & & 3 & 4 & & 7 \\
\hline Bladder & & 1 & 1 & & & & & & 2 \\
\hline Breast & 7 & 21 & 8 & & 3 & 6 & 6 & & 39 \\
\hline Head and Neck & 1 & & & 1 & & & & & 2 \\
\hline Prostate & & 10 & 3 & & & 3 & 6 & & 16 \\
\hline Neuroendocrine & & 1 & & & & & & & 1 \\
\hline Non-Hodgkin's lymphoma & 1 & 6 & & & & 1 & 3 & & 8 \\
\hline Non-small cell lung & & & 2 & & & 2 & 2 & & 2 \\
\hline Colorectal & 1 & & 9 & 2 & 1 & 6 & & & 13 \\
\hline Pancreatic & & & 2 & & & 2 & 2 & & 4 \\
\hline Ovarian & & & 5 & 1 & & 3 & 1 & & 6 \\
\hline Miscellaneous & 2 & 6 & 5 & 1 & 1 & 1 & & 1 & 15 \\
\hline Total & 12 & 45 & 43 & 8 & 5 & 27 & 28 & 1 & 119 \\
\hline
\end{tabular}

feel it is a route for them. The cannabis products they use vary, and can be in the form of whole-plant extracts or purified oils; however, whatever the source, they self-prescribe dosages. A number of anecdotal positive responses have been reported, which sustains the interest in this type of medication.

In order to assess its potential use, we focused on giving patients with advanced cancer who requested CBD a pharmaceutical-grade synthetic product at appropriate doses. Activity of synthetic cannabinoid WIN on human cancer cell lines has been reported (9). Every patient in this study signed an informed consent allowing anonymous use of their data.

\section{Case Presentations}

Patients were given synthetic, pharmaceutical-grade CBD (STI Pharmaceuticals), registered under the Pharmaceutical Specials scheme in oily drops at 5\% (w/v) in $20 \mathrm{ml}$ bottles. Each drop contained $1 \mathrm{mg}$ of synthetic CBD in neutral oil. This was prescribed on an informed consent basis. 119 cancer patients decided to have this treatment (Table I), and most of them had metastatic cancers. Of the 119 patients, 28 were given CBD as the only treatment. A third of these patients had already been taking cannabis oil extracted from the cannabis plant that had been bought on the Internet, with no beneficial response. This is currently illegal, as the Medicines and Health Regulatory Agency has defined CBD as a medicinal product, which can only be prescribed under the Pharmaceutical Specials scheme, as it is not currently a licensed medicinal product (10).

The majority of the patients were assessed using a circulating tumour cell test before and after treatment (11), since this is cheaper than carrying out repeated scans. A number of patients however, as a matter of a normal treatment course, had relevant scans. CBD was administered on three days on and three days off basis, which clinically was found to be more effective than giving it as a continuous dose. The average dose was $10 \mathrm{mg}$ twice a day. For increased tumour mass, the dose was increased, in some cases up to 30 drops twice a day $(30 \mathrm{mg})$. In a number of cases where stable disease was present, the dose was reduced to five drops twice a day $(5 \mathrm{mg})$. In some cases, Sativex, which is licensed for use in multiple sclerosis, was used in conjunction with CBD as a source of THC, which synergises with CBD (12). A fraction of the dose used for multiple sclerosis was used. Two sprays of Sativex were given twice a day in three days on and three days off pattern, as in the case of pharmaceutical-grade synthetic CBD; patients on continuous dosing did not do as well as those on this on-off repeating regimen. Some of our patients reverted to cannabis oil bought on the Internet, and following this, $80 \%$ of these cases relapsed.

We were unable to define a maximum tolerated dose for $\mathrm{CBD}$, as there was a complete absence of side effects. The minimum duration of treatment required for CBD was six months, but many continued for longer. Less than six months appeared inadequate and had little effect, and therefore cases in which CBD was used for less than six months have been defined as un-assessable, and not included in the current cohort of 119 cases.

We sought clear objective evidence of potential efficacy where no other treatment option was available. The most impressive case was a five-year-old male patient with an anaplastic ependymoma, a very rare brain tumour. The patient had had all standard treatments, surgery on two occasions followed by chemotherapy and conformal photon 
A

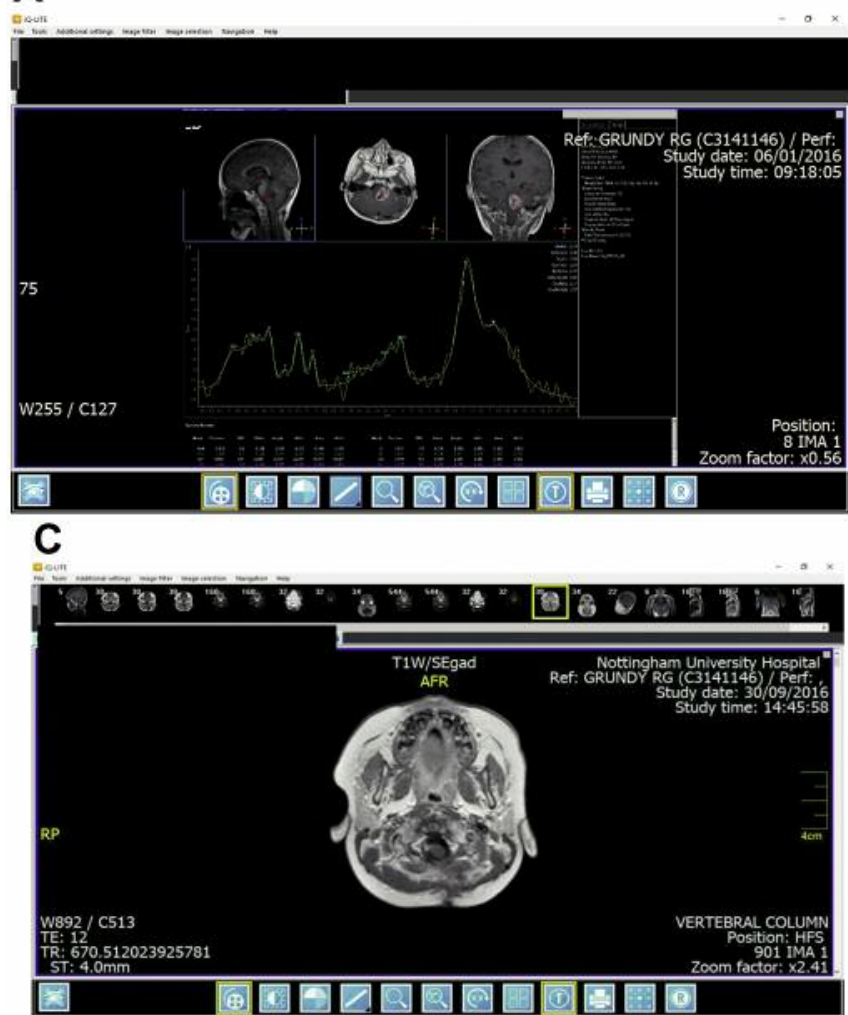

B

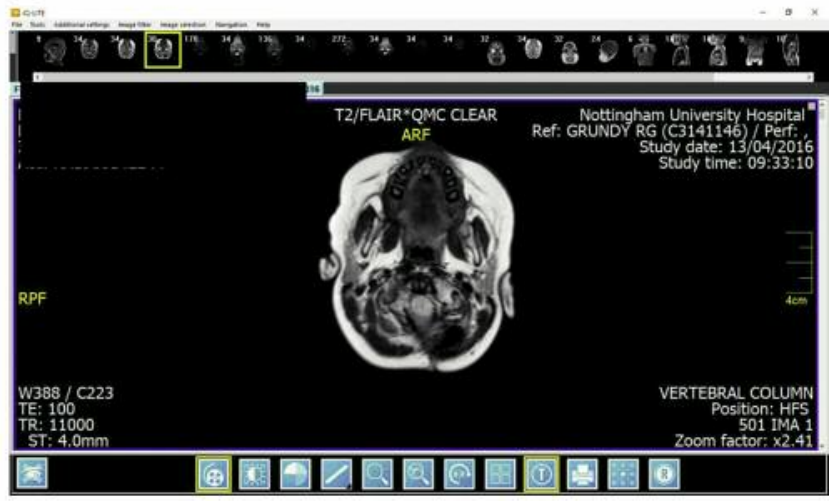

D

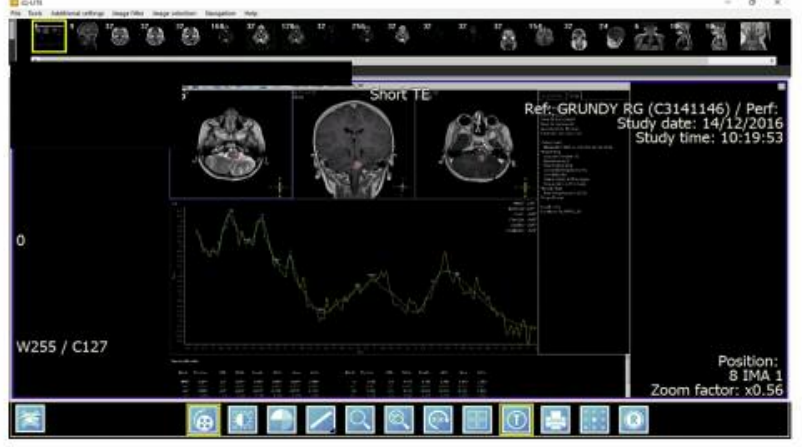

Figure 1. Patient with ependymoma. A) A scan on the 6th of Jan 2016 showed enlargement of the posterior fossa mass. There were some, particularly multimodal features of radionecrosis, but in the context of a previously rapidly progressive tumour, an element of disease progression was also being considered. B) A subsequent scan on the 13th April 2016 showed further tumour progression and development of moderately severe supratentorial hydrocephalus. C) On the 30 Sept 2016, scans showed substantial improvement/reduction in size of the residual disease. There had been a substantial improvement in appearances, with marked reduction in size of the posterior fossa tumour from $3.4 \times 3.2 \mathrm{~cm}$ in the sagittal plane to $1.7 \times 1.7 \mathrm{~cm}$. D) Scans performed on the 14th Dec 2016, showed a slow improvement; with impressive resolution of left CPA recurrent ependymoma.

A

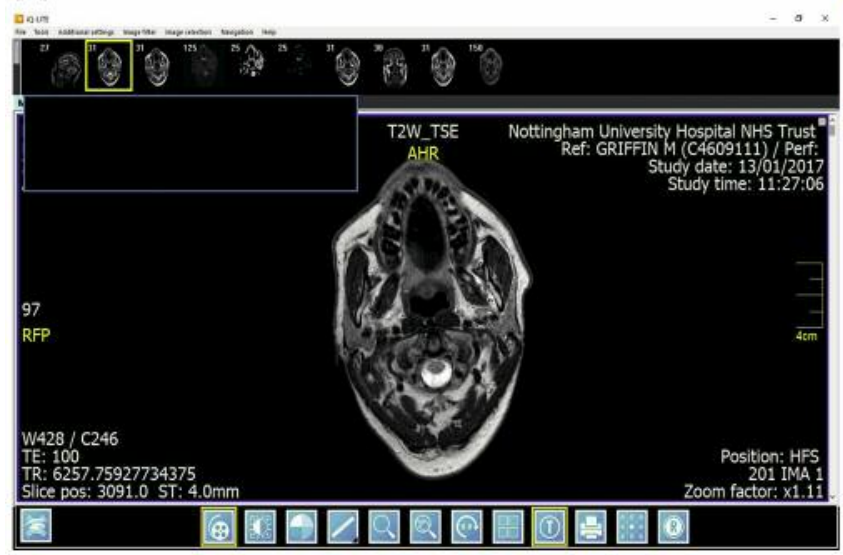

B

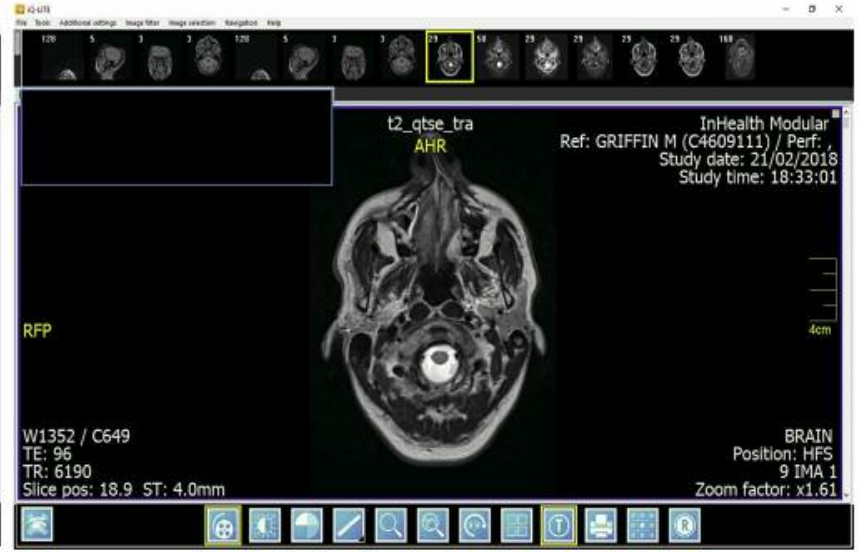

Figure 2. Patient with tanycytic ependymoma. A) A scan on the 13th Jan 2017 showed a reduction in the size and enhancement of the left periventricular tumour. There was almost complete resolution of the parenchymal enhancement with a couple of small ependymal nodules remaining, but slightly smaller. There was no significant change in the T2/FLAIR appearance with Wallarian degeneration extending into the corticospinal tracts. B) A followup scan performed on the $21 \mathrm{Feb} 2018$ revealed evidence of disease progression with a near doubling of the enhancing soft tissue arising from the ependymal surface of the left lateral ventricle and projecting into the body of the left lateral ventricle. There are new enhancing foci in the left putamen and subthalamic region with further non-enhancing T2 hyperintense tumour expanding inferiorly into the left cerebral peduncle. 
Table II. Examples of patients who have been using pharmaceutical-grade synthetic CBD.

\begin{tabular}{|c|c|c|}
\hline Age/Gender & Diagnosis & Comments \\
\hline $72 /$ male & Prostate cancer & $\begin{array}{l}\text { Patient has had cancer immunotherapy, sono and photodynamic therapy (14) which was successful. } \\
\text { On resumption of testosterone injections his prostate specific antigen (PSA) levels increased } \\
\text { to } 16 \text {. We started him on CBD early in } 2015 \text { at a dose of } 10 \text { drops twice a day (10 mg), } \\
\text { three days on and three days off. There was a reduction in circulating tumour cells (CTCs) with } \\
\text { CBD alone from an initial } 8.1 \text { cells } / 7.5 \mathrm{ml} \text { to } 5.9 \text { cells } / 7.5 \mathrm{ml} \text {, then steady reduction over the } \\
\text { course of } 12 \text { months of } 4.8,4.2 \text { then } 3.2 \text { cells } / 7.5 \mathrm{ml} \text {. He is still under treatment. }\end{array}$ \\
\hline $68 /$ female & $\begin{array}{c}\text { Breast cancer with } \\
\text { bone metastases }\end{array}$ & $\begin{array}{l}\text { Patient was diagnosed in March } 2014 \text { with progressive disease. } \\
\text { She started local radiotherapy. We started her on CBD in January 2015, all subsequent } \\
\text { scans showed stable disease. She has had no treatment other than CBD following radiotherapy. }\end{array}$ \\
\hline $65 /$ female & Oesophageal cancer & $\begin{array}{l}\text { Patient was diagnosed in May 2016. She had a stent put on place at that time and was given } \\
\text { an expected survival of three months. Since then, she has been on CBD as the only } \\
\text { treatment, and she has continued to refuse all standard treatments and investigations. } \\
\text { We last saw her in November 2016, when she was looking well and } \\
\text { had in fact regained weight. She died in January } 2018 .\end{array}$ \\
\hline $65 /$ female & Breast cancer & $\begin{array}{l}\text { Patient was diagnosed in November } 2009 \text {, and refused all conventional treatments } \\
\text { and investigations. On examination she had a large fungating lesion } 15 \mathrm{~cm} \text { in diameter in the } \\
\text { left breast, and also palpable left axillary nodes. She began treatment with CBD } \\
\text { in October } 2014 \text {. We persuaded her to have radiotherapy in November } 2014 \text {. } \\
\text { She only agreed to have half the recommended treatment course. She has continued } \\
\text { on CBD alone and on her last appointment the tumour in her left } \\
\text { breast was } 2 \mathrm{~cm} \text { in diameter, with no palpable axillary nodes. }\end{array}$ \\
\hline $62 /$ female & Breast cancer & $\begin{array}{l}\text { We first saw this patient in May } 2014 \text { and she has been on CBD, } \\
\text { as the only treatment, since October } 2014 \text {. We carried out various CTC tests } \\
\text { in October } 2014 \text { which showed } 10.6 \text { cells per } 7.5 \mathrm{ml} \text {. Subsequent tests in July and } \\
\text { October } 2015 \text {, November } 2016 \text { and October } 2017 \text { showed CTCs to be } 7.3,6.8,5.0 \\
\text { and } 3.9 \text { cells } / 7.5 \mathrm{ml} \text {, respectively. Patient is currently stable with no symptoms. }\end{array}$ \\
\hline 67/female & $\begin{array}{c}\text { Lobular breast } \\
\text { cancer }\end{array}$ & $\begin{array}{l}\text { Patient was diagnosed in November 2012. We first saw her in March 2014, } \\
\text { we gave her CBD in October 2014, which is the only method of treatment. Initial CTCs in } \\
\text { October } 2014 \text { was } 9.3 \text { cells per } 7.5 \mathrm{ml} \text {. Follow-up measurements in September } 2015 \text {, March } 2016 \\
\text { and March } 2017 \text { have been } 7.5,6.8 \text { and } 3.0 \text { cells } / 7.5 \mathrm{ml} \text {, respectively. All standard } \\
\text { clinical investigations and scans have been normal since the beginning of } 2015 \text {. }\end{array}$ \\
\hline
\end{tabular}

radiotherapy. No further treatment options were available to him when treatment on CBD started in February 2016. A scan carried out in December 2016 showed that tumour volume had decreased by $\sim 60 \%$. Further scans, carried out since December 2016, continued to show stable disease. CBD was the only treatment. Four scans with the scan report at the top of each scan are appended (Figure 1A-D).

Another impressive case was a 50-year-old patient with progressive tanycytic ependymoma Grade 2 diagnosed in June 2013, treated with biopsy and radical radiotherapy, which was completed on 3rd June 2015. He refused chemotherapy, and had no further treatment options. He started on pharmaceutical-grade synthetic CBD in July 2016 at a dose of 10 drops twice a day, three days on and three days off $(10 \mathrm{mg})$. Prior to this he had been taking, for some time, metformin, mebendazole, doxycycline and atorvastatin from an oncology clinic in Central London.

In January 2017 a repeat scan showed tumour reduction. At that point the patient stopped taking pharmaceutical-grade synthetic CBD and switched to cannabis oil extract obtained from an internet website. Further scans carried out in February 2018 showed doubling of tumour size and more growth down the brain stem. He has since restarted pharmaceutical-grade synthetic CBD and throughout continued to take the metformin, atorvastatin, doxycycline and mebendazole. So, the only change in November 2017 had been stopping the pharmaceutical-grade synthetic CBD and switching to cannabis oil extract obtained on the Internet (Figure 2A and B).

Other patients who clearly improved using pharmaceuticalgrade synthetic CBD had prostate cancer, breast cancer, oesophageal cancer and a lymphoma, and these are summarised in Table II.

\section{Discussion}

From our laboratory studies, we would not expect any significant anti-cancer activity using continuous CBD alone, as we have only observed cancer cell line apoptosis (cell 
death) when the agent is washed out of culture and withdrawn (13). We have also observed a potential increased cell killing ability when given after chemotherapy.

Cannabinoids have an accepted useful role in the management of cancer symptoms, namely pain control, nausea and cachexia, but not as part of primary treatment. The fact that we have been able to document improvement in cancer in few patients strongly supports further studies of CBD-based products in cancer patients who have exhausted standard treatments. Our primary data in a murine glioma model (14) showing enhanced sensitivity to radiotherapy without any side-effects, suggests this would be an ideal clinical trial to initiate in the first instance.

\section{Conflicts of Interest}

There are no conflicts of interest to disclose.

\section{References}

1 Pertwee RG: The pharmacology of cannabinoid receptors and their ligands: an overview. Int J Obes 30: S13-18, 2006.

2 Guzmán M, Duarte MJ, Blázquez C, Ravina J, Rosa MC, GalveRoperh I, Sánchez C, Velasco G and González-Feria L: A pilot clinical study of Delta9-tetrahydrocannabinol in patients with recurrent glioblastoma multiforme. Br J Cancer 95: 197-203, 2006.

3 WHO Online Q\&A. Cannabidiol (compound of cannabis) December 2017. http://www.who.int/features/qa/cannabidiol/en/ (accessed March 2018)

4 Massi P, Solinas M, Cinquina V and Parolaro D: Cannabidiol as potential anticancer drug. Br J Clin Pharmacol 75: 303-312, 2013.

5 Scott KA, Dalgleish AG and Liu WM: Anticancer effects of phytocannabinoids used with chemotherapy in leukaemia cells can be improved by altering the sequence of their administration. Int J Oncol 51: 369-377, 2017.

6 Scott KA, Shah S, Dalgleish AG and Liu WM: Enhancing the activity of cannabidiol and other cannabinoids in vitro through modifications to drug combinations and treatment schedules. Anticancer Res 33: 4373-4380, 2013.
7 Brown MRD and Farquhar-Smith WP: Cannabinoids and cancer pain: A new hope or a false dawn? Eur J Intern Med 49: 30-36, 2018.

8 Bar-Lev Schleider L, Mechoulam R, Lederman V, Hilou M, Lencovsky O, Betzalel O, Shbiro L and Novack V: Prospective analysis of safety and efficacy of medical cannabis in large unselected population of patients with cancer. Eur J Intern Med 49: 37-43, 2018.

9 Müller L, Radtke A, Decker J, Koch M and Belge G: The Synthetic Cannabinoid WIN 55,212-2 Elicits Death in Human Cancer Cell Lines. Anticancer Res 37: 6341-6345, 2017.

10 MHRA. Regulatory status of products containing CBD, published 13th October 2016, updated 30th December 2016 https://www.gov.uk/government/news/mhra-statement-onproducts-containing-cannabidiol-cbd

11 Papasotiriou I, Chatziioannou M, Pessiou K, Retsas I, Dafouli G, Kyriazopoulou A, Toloudi M, Kaliara I, Vlachou I, Kourtidou E, Kipourou V, Georgiou E, Ntanovasilis DA, Theodosiou C, Pantopikou A and Apostolou P: Detection of circulating tumor cells in patients with breast, prostate, pancreatic, colon and melanoma cancer: A blinded comparative study using healthy donors. J Cancer Ther 6: 543-553, 2015.

12 Scott KA, Dalgleish AG and Liu WM: The combination of cannabidiol and $\Delta 9$-tetrahydrocannabinol enhances the anticancer effects of radiation in an orthotopic murine glioma model. Mol Cancer Ther 13: 2955-2967, 2014.

13 Scott KA, Shah S, Dalgleish AG and Liu WM: Enhancing the activity of cannabidiol and other cannabinoids in vitro through modifications to drug combinations and treatment schedules. Anticancer Res 33: 4373-4380, 2013.

14 Kenyon JN, Fuller RJ and Lewis TJ: Activated cancer therapy using light and ultrasound - a case series of sonodynamic photodynamic therapy in 115 patients over a 4-year period. Curr Drug Ther 4: 179-193, 2009.
Received August 22, 2018

Revised September 12, 2018

Accepted September 21, 2018 